\title{
PRECONCEITO LINGUÍSTICO E ASPECTOS JURÍDICOS: A INCLUSÃO POLÍTICA ATRAVÉS DA ALFABETIZAÇÃO NO SÉCULO XXI
}

\section{Lázaro Alves Borges*}

Resumo: O artigo visa avaliar a restrição constitucional dos políticos do analfabeto, no tocante ao impedimento a possibilidade de ser votado (passivo) aos cargos do Legislativo. Questiona-se se num país em que o analfabetismo, ainda na sua forma funcional, haveria razoabilidade na manutenção da proibição. Observar-se-á, no histórico das Cartas Brasileiras e se não há um preconceito com a inexistência ou o mau uso do vernáculo como forma de manutenção de um status quo. Conclui pela releitura da proibição constitucional face aos pronunciamentos internacionais e a cláusula de proteção expansiva dos direitos fundamentais.

Palavras-chave: Inelegibilidade. Preconceito linguístico. Comitê de Combate à Todas as Formas de Desigualdade Racial. Analfabetização.

\section{LANGUAGE PREVENTION AND LEGAL ASPECTS: POLITICAL INCLUSION THROUGH LITERACY IN THE 21ST CENTURY}

\begin{abstract}
The article aims to evaluate the constitutional restriction of politicians of the illiterate, regarding the impediment the possibility of being voted to congressmen and senators. It is questioned whether in a country where illiteracy, still in its functional form, would be reasonable in maintaining the prohibition. It will be noted in the history of the Brazilian Letters and if there is no prejudice with the inexistence or misuse of the vernacular as a way of maintaining a status quo. It concludes by re-reading the constitutional prohibition in the face of international pronouncements and the expansive protection of fundamental rights clause.
\end{abstract}

Key words: Ineligibility. Linguisticprejudice. Committee to Combat All Forms of Racial Inequality. Analfabetization.

\section{INTRODUÇÃO}

A Constituição Cidadã de 1988 avançou em diversos aspectos no campo dos direitos políticos: estabeleceu o pluripartidarismo, democracia participativa (BARREIROS NETO, 2018) ${ }^{1}$, ampliou a possibilidade de manifestação político-partidária com resposta ao período ditatorial (GUIMARÃES,2011). Todavia, quanto ao exercício do voto, permaneceram retrocessos no tocante aos analfabetos, enfoque desse trabalho. Isso porque, conforme

\footnotetext{
${ }^{1}$ Segundo Jaime Barreiros Neto (2018), a democracia brasileira contém elementos de indireta, com a eleição de seus representantes políticos (congressistas, chefes do Poder Executivo nas escalas) e direta, com a possibilidade de leis de inciativa popular, autorizar referendo e convocar plebiscito, configurando uma democracia semidireta ou participativa.
}

Rev. de Teorias da Justiça, da Decisão e da Argumentação Jurídica | e-ISSN: 2525-9644 | Porto Alegre | v. 4 | n. 2 | p. 01 - 15 | Jul/Dez. 2018 
disposto no art. 14, o analfabeto é facultado o direito ao voto, todavia não pode ser votado, o que é um discrimine jurídico a ser observado no tocante à proporcionalidade e à razoabilidade da proibição. Ressalta-se que, sendo norma constitucional originária e definidora de direitos e de garantias fundamentais, os entraves jurídicos para modificar a restrição são distintos da simples inconstitucionalidade da lei, o que será observado posteriormente.

Segundo dados do Instituto de Pesquisa Econômica Aplicada (IPEA), enquanto os brancos são $6,1 \%$ dos analfabetos, os negros registram 14,1\%. Salienta que,na área urbana tem-se o menor número de analfabetos, com 4,4\%, do quena zona rural, com $23,3 \%{ }^{2}$. Portanto, os analfabetos são minorias esquecidas no discurso político-constitucional, o qual se voltam a grupos estruturados com movimento black, minorias sexuais, minorias de gênero, nordestinos, dentre outros. Distintamente dos apresentados, ser analfabeto é um estigma social, por não compreender signos e símbolos compartilhados, não competir em igualdades de condições e, pela restrição de informação, não poder pautar no Congresso Nacional ou na mídia suas principais reivindicações, necessitando de terceiros.

Diante do exposto, objetiva o artigo: (a) observar qual o papel da escrita como interação social e construção da cidadania, num viés histórico e político, a fim de observarcomo se construiu a inevitável compreensão de signo e de símbolos e a interface com o Estado Moderno; (b) estabelecer um histórico das inelegibilidades no direito eleitoral brasileiro com o papel de segregar minorias do processo político de escolha; (c) analisar as manifestações do Comitê de Combate à Desigualdade Racial instituído pela Convenção Internacional sobre a Eliminação de Todas as Formas de Discriminação Racial sobre o dispositivo constitucional; (4) observar a existência de possível preconceito linguístico de maneira ampla - uso da língua oral e escrita de forma desviada da norma padrão - e das línguas não-portuguesas de grupos vulneráveis (indígenas não-integrados); (5) elencar possíveis soluções para a interpretação do art. 14 da Constituição Federal quanto ao analfabeto de língua portuguesa (manutenção, mutação, reforma formal da proibição de se candidatar e da facultatividade do voto).

Ressalta-se a importância do artigo ao estudo do direito das minorias, notadamente raciais e hipossuficientes. Há uma relevância na discussão, posto que almeja a interpretação provulnerável no tocante a usual descrição doutrinária do analfabeto. Ademais, academicamente, pela impossibilidade de escrita, nenhum de seus representantes, usualmente,

\footnotetext{
${ }^{2}$ Dados do Instituto de Pesquisa Econômicas Aplicadas, acessado em 23.07.2018.
} 
terá acesso à defesa de seus direitos neste âmbito, repercutindo posicionamentos de manutenção do status quo, sobretudo pela inegável premente necessidade de erradicação do analfabetismo no país, dever constitucional constante no art. 214 I, e do desenvolvimento socioeconômico.

Nesse artigo, recortar-se-á como objeto de estudo para a discussão sobre as eleições tão somente do Legislativo, norteadas pelo princípio republicano e democrático, de composição plural. Argumentos que seriam válidos aos chefes do Poder Executivo (de caráter unipessoal) não foram explorados por extrapolar o estudo. O trabalho intercambia-se nodireito das minorias, no direito eleitoral, em aspectos sociojurídicos e nas liberdades públicas.

\section{O PAPEL DA ESCRITA NA FORMAÇÃO DA CONSTRUÇÃO DA CIDADANIA}

Numa perspectiva historiográfica, o sistema de escrita originou-se de uma necessidade econômica (HARARI, 2018) ${ }^{3}$. O sistema de registro de impostos e de burocracias complexas,originaram-se concomitante ao sistema de escrita parcial e permanece unido até os dias atuais. A Suméria, o Egito, a China e Império Inca desenvolveram boas técnicas de arquivamento, catalogação e consulta dos escritos, bem como formação para escribas, escriturários, bibliotecários e contadores. Assim, a habilidade da escrita corrobora para a instituição de uma classe diferenciada e da possibilidade de ingressar no âmbito do Estado. Assim, mudou-se a forma de pensamento do mundo: do pensamento holístico e livre associação à compartimentalização e burocracia, sempre associada à processualização do Estado (CHIAVENATO, 2004, p.138).

Povos já foram discriminados através de sua forma de escrita: os romanos observavam as línguas dos bárbaros como de menor prestígio, com menor léxico (BETHENCOURT, 2018). A literatura clássica, com enfoque eurocêntrica, discrimina a produção literária de povos africanos e árabes por apresentar estilística distinta (SCHWARTZ, 2018). No Brasil hodierno, a própria Constituição Federal institui a língua portuguesa como oficial e, distintamente do Estado Plurinacional da Bolívia - aquele que reconhece uma diversidade de nações dentro do seu espaço geográfico, constituindo não só

\footnotetext{
${ }^{3}$ No Império Inca, os quipos - praticamente destruídos atualmente depois da colonização espanhola - foram essenciais ao negócio das cidades, reinos e impérios para salvar processar grandes quantidades de dados para manter o complexo maquinário administrativo(HARARI, 2018, p. 135 ess).
}

Rev. de Teorias da Justiça, da Decisão e da Argumentação Jurídica | e-ISSN: 2525-9644 | Porto Alegre | v. 4 | n. 2 | p. 01 - 15 | Jul/Dez. 2018 
dos descendentes de espanhóis, mas de todos os povos indígenas -, ocasiona uma discriminação com base no costume de um sistema léxico em detrimento de outros. Como exemplo,cita-se o indígena isolado como os Awá (OS ÍNDIOS ..., 2018), que serão considerados analfabetos no sistema constitucional, se somente souber sua língua materna.Tal prática é um contrassenso lógico, posto que a própria Carta Magna assegura, no art. 231, o reconhecimento dos seus costumes, línguas e tradições ${ }^{4}$.

No âmbito jurídico-constitucional, a habilidade com a escrita cria condições formais para a acessibilidade a determinados setores como acesso ao ensino superior ${ }^{5}$, aos cargos públicos ${ }^{6}$, um incentivo à promoção da educação como forma de erradicação do analfabetismo $^{7}$ e, no que tange a este trabalho, na restrição de direitos políticos.

Nesse mister, ressalta-se que a erradicação do analfabetismo no Brasil é uma política pública que deve ser perseguida pelo gestor, posto que se baseia no objetivo fundamental de erradicar a pobreza e a marginalização bem como de reduzir as desigualdades sociais e regionais $^{8}$. Não se pretende atenuar a responsabilidade do Estado em educar os seus cidadãos, constituindo num dever fundamental à educação (MARTINS, 2011. p. 40). Deve-se levar em conta se não há outros meios de participação da vida política que não interno ao sistema

\footnotetext{
${ }^{4}$ Art. 231 da Constitucional Federal. São reconhecidos aos índios sua organização social, costumes, línguas, crenças e tradições, e os direitos originários sobre as terras que tradicionalmente ocupam, competindo à União demarcá-las, proteger e fazer respeitar todos os seus bens.

${ }^{5}$ Art. 208 da Constituição Federal. O dever do Estado com a educação será efetivado mediante a garantia de: V acesso aos níveis mais elevados do ensino, da pesquisa e da criação artística, segundo a capacidade de cada um; Nesse sentido, tornou-se usual a realização de certames públicos (vestibulares) a fim de selecionar os candidatos mais aptos ao exercício de determinada atividade.

${ }^{6}$ Art. 37 II da Constituição Federal: a investidura em cargo ou emprego público depende de aprovação prévia em concurso público de provas ou de provas e títulos, de acordo com a natureza e a complexidade do cargo ou emprego, na forma prevista em lei, ressalvadas as nomeações para cargo em comissão declarado em lei de livre nomeação e exoneração;

$\mathrm{O}$ entendimento ordinariamente é que as provas devem ser objetivas e majoritariamente escrita. Nesse sentido, o entendimento dos órgãos de controle é de objetivação do certame com regras que um analfabeto provavelmente não acessará.

${ }^{7}$ Art. 214 da Constituição Federal:. A lei estabelecerá o plano nacional de educação, de duração decenal, com o objetivo de articular o sistema nacional de educação em regime de colaboração e definir diretrizes, objetivos, metas e estratégias de implementação para assegurar a manutenção e desenvolvimento do ensino em seus diversos níveis, etapas e modalidades por meio de ações integradas dos poderes públicos das diferentes esferas federativas que conduzam a: I - erradicação do analfabetismo;

8 Art. $3^{\circ}$ Constituem objetivos fundamentais da República Federativa do Brasil:

I - construir uma sociedade livre, justa e solidária;

II - garantir o desenvolvimento nacional;

III - erradicar a pobreza e a marginalização e reduzir as desigualdades sociais e regionais;

IV - promover o bem de todos, sem preconceitos de origem, raça, sexo, cor, idade e quaisquer outras formas de discriminação.
}

Rev. de Teorias da Justiça, da Decisão e da Argumentação Jurídica | e-ISSN: 2525-9644 | Porto Alegre | v. 4 | n. 2 | p. 01 - 15 | Jul/Dez. 2018 


\section{PRECONCEITO LINGUÍSTICO E ASPECTOS JURÍDICOS: A INCLUSÃO POLÍTICA ATRAVÉS DA ALFABETIZAÇÃO NO SÉCULO XXI}

educacional, considerando a liberdade individual, máxima a ser preservada por um Estado Democrático de Direito.

Pode-se argumentar que a capacidade de ler e de escrever capacitaria ao eleitor a uma posição política consolidada, pouco influenciável à manipulação política e à política do coronelismo (MAIA, 2012), porquanto permite o acesso às realidades distintas, pluralidade de ideias, verdade científica. Todavia, esse argumento corrobora, se aplicado de forma ideal, a uma sofocracia (PLATÃO, 2016) - governo de sábios -, em que num contexto de desigualdades sociais, sobrepõem os que puderam ter uma educação formal (mais ricos) àqueles que não tiveram oportunidade por inexistência ou precariedade do sistema de ensino 9 . Além disso, reduz a possibilidade de experiências humanas e de saberes àqueles passados pelo sistema formal, desconsiderando outros aspectos da vida em comunidade (aprendizado religioso, inteligência emocional, cultura local). A escola, muito embora seja uma fonte de aprendizado, também é uma instituição que exerce poder e doutrinação perante o indivíduo (FOUCAULT, 2008. p. 30).

A situação se agrava ao se observar o número de analfabetos funcionais - os que não compreendem textos simples ou não conseguem fazer operações matemáticas básicas. Em estudo do Analfabetismo no Mundo do Trabalho, apenas 8\% dos brasileiros possuem proeficiência no uso do vernáculo, isto é, não têm aptidão para atuar no mercado de trabalho de forma que atenda as expectativas como: escrever e-mails simples, interpretar textos corridos, interpretar tabelas e gráficos (ANALFABETISMO...,2018), o que se espera de um eleitor ordinário, intenção do constituinte em realizar este discrimine.

Nesse sentido, o Instituto de Pesquisas Econômicas Aplicadas (IPEA) apontou para que a maior parte dos analfabetos não sabem nem ler nem escrever. A primeira conclusão que se pode ter é sobre a representação dos brasileiros no Congresso Nacional, que normalmente não se assemelha à população, o que gera uma crise de representatividade. Num espaço em que a diversidade tem como pressuposto (eleição por princípio proporcional, que visa representar a população) $)^{10}$.

\footnotetext{
${ }^{9}$ Art. 208. O dever do Estado com a educação será efetivado mediante a garantia de:

I - educação básica obrigatória e gratuita dos 4 (quatro) aos 17 (dezessete) anos de idade, assegurada inclusive sua oferta gratuita para todos os que a ela não tiveram acesso na idade própria; (Redação dada pela Emenda Constitucional $n^{\circ} 59$, de 2009) (Vide Emenda Constitucional $n^{\circ} 59$, de 2009)

${ }^{10}$ Art. $45 \S 1^{\circ}$ da Constituição Federal: O número total de Deputados, bem como a representação por Estado e pelo Distrito Federal, será estabelecido por lei complementar, proporcionalmente à população, procedendo-se
}

Rev. de Teorias da Justiça, da Decisão e da Argumentação Jurídica | e-ISSN: 2525-9644 | Porto Alegre | v. 4 | n. 2 | p. 01 - 15 | Jul/Dez. 2018 


\section{INELEGIBILIDADES E DIREITO AO VOTO NO DIREITO BRASILEIRO}

A tradição constitucional brasileira apontou, sempre, para a distinção dentre aqueles que poderiam votar e ser votados. No plano legislativo, comum a instituição de restrições ao voto e de inelegibilidades, que, segundo Dirley da Cunha Junior, são aquelas que anulam, total ou parcialmente a prerrogativa do cidadão ser eleito, obstando-lhe de assumir os mandatos eletivos (absolutas) ou para determinados cargos (relativos) a fim de proteger a moralidade (CUNHA JUNIOR, 2016. p. 700). Todavia, embora afronte a moral comum, a moral jurídica não deve ser afrontada, posto que o analfabeto é reflexo do nosso povo, cuja razoabilidade de sua eleição encontra-se na restrição ao direito e não ao mau uso da máquina pública.

Passa-se a realizar um escorço histórico do exercício dos direitos políticos no Brasil. Já na Constituição Imperial de 1824, adotou-se o voto censitário, que restringia a possibilidade de voto das mulheres, escravos e daqueles que não obtinham renda. Todavia, a limitação de renda tinha pouca importância por sua baixa estipulação. Em 1876, o menor salário era de 600 mil reis (as da Inglaterra eram muito mais altas). A lei brasileira permitia o voto dos analfabetos (CARVALHO, 2018. p. 36). Dados sobre o cidadão médio revelam que $85 \%$ eram analfabetos, incluído grandes proprietários rurais, $90 \%$ residia em áreas rurais sob controle dos proprietários e, nas cidades, a maior parte era funcionários públicos controlados pelo Governo (CARVALHO, 2018. p. 37-38). Assim, proibir o exercício da democracia aos analfabetos era um contrassenso lógico.

Em 1881, a Câmara dos Deputados aprovou a lei que introduzia o voto indireto, eliminando o primeiro turno das eleições (haveria somente eleitores). Ao mesmo tempo, passava para 200 mil-réis a exigência de renda (que não era alto, mas a lei era rígida na maneira de demonstração da renda, o que limitou pessoas que poderiam votar), proibindo o voto dos analfabetos e tornando o voto facultativo (CARVALHO, 2018. p. 44). Se em 1872, havia mais de 1 milhão de votantes (13\% da população livre), em 1886, votaram 100 mil

aos ajustes necessários, no ano anterior às eleições, para que nenhuma daquelas unidades da Federação tenha menos de oito ou mais de setenta Deputados.

Rev. de Teorias da Justiça, da Decisão e da Argumentação Jurídica | e-ISSN: 2525-9644 | Porto Alegre | v. 4 | n. 2 | p. 01 - 15 | Jul/Dez. 2018 


\section{PRECONCEITO LINGUÍSTICO E ASPECTOS JURÍDICOS: A INCLUSÃO POLÍTICA ATRAVÉS DA ALFABETIZAÇÃO NO SÉCULO XXI}

eleitores $(0,8 \%$ da população total). O Brasil caminhava na contramão do mundo, que ampliava os direitos políticos.

A proclamação da república em 1889 não alterou o quadro. A Constituição de 1891 não permitiu o voto dos analfabetos, eliminando a renda. Não votavam as mulheres, os mendigos, os soldados e os membros de ordens religiosas. Em 1894, votaram 2,2\%. Em 1930, 5,6\%. Somente em 1945, compareceram às urnas 13,4\% (número superior a 1872) (CARVALHO, 2018. p. 47).

Ilustrando os números apontados, observa-se que na literatura de Lima Barreto, no romance "Os Bruzundangas”, há uma descrição de uma república imaginária em que "[...] os políticos práticos tinham conseguido quase totalmente eliminar do aparelho eleitoral este elemento perturbador - o voto" (SCHWARTZ, 2018).

Após 1945, o ambiente internacional tornou-se favorável à democracia. O voto estendeu-se a todos os cidadãos, homens e mulheres com mais de 18 anos de idade (obrigatório, secreto e direto) numa época em que $57 \%$ da população era analfabeta, restringindo apenas aos soldados das forças armadas.

Nesse contexto, houve otimismo nas eleições de 1986 para formar a Assembleia Nacional Constituinte ( $4^{\mathrm{a}}$ da República). A Constituinte fez amplas consultas à especialistas e aos setores organizados e representativos da sociedade. Finalmente, em 1988, foi promulgada a Constituição de 1988. Esta carta eliminou o obstáculo à universalidade do voto, tornando-o facultativo aos analfabetos, embora a redução do número de analfabetos, em 1990, ainda eram 30 milhões de brasileiros ( $8 \%$ dos eleitores). A Constituição foi liberal no critério etário fixando a possibilidade para 16 anos. A única proibição que permaneceu foi aos conscritos (que embora injustificada atinente parcela mínima da população e durante período curto de vida). Os porcentuais de participação das eleições são incomparáveis a de qualquer outro país democrático moderno. Todavia, quanto à possibilidade de ser votado, remanesce a proibição no sistema jurídico para os analfabetos.

Da mesma forma que a hierarquia de ricos e de pobres é falaciosa, pois a maior parte dos ricos o são pelo motivo de terem nascido em famílias ricas, enquanto que a maior parte dos pobres continuarão na mesma condição do nascimento(HARARI, 2018. p. 143), idêntica situação pode ser a daqueles que possuíram acesso à educação formal e a alfabetização de qualidade: a maior parte dos filhos de alfabetizados o serão, seja pela inclusão nos meios

Rev. de Teorias da Justiça, da Decisão e da Argumentação Jurídica | e-ISSN: 2525-9644 | Porto Alegre | v. 4 | n. 2 | p. 01 - 15 | Jul/Dez. 2018 
tradicionais de ensino (escolas), seja pela transmissão do conhecimento no seio familiar. Assim, incumbe ao Estado a responsabilidade pela educação daqueles que não tiveram na idade própria, sobretudo por ausência de inserção da cultura educacional nas gerações anteriores (lógica de retroalimentação do analfabetismo).

Com o advento das tecnologias digitais, discute-se acerca da necessidade de escrita por parte do falante. Isso porque, há uma progressiva substituição do papel escrito e do desenho dos símbolos usuais pela digitação e pela inserção de documentos via Internet. $\mathrm{O}$ conceito de alfabetização tem modificado para a possibilidade, do educando,de ir além do desenho de seu nome civil, abarcando ainda a compreensão de pequenos textos, ainda que digitalizados.Futuramente, em décadas, se resistir a proibição ao analfabeto, o exame realizado perante a Justiça Eleitoral deve ser substituído por teste similar com um computador e a capacidade de leitura e escrita nos meios informáticos.

Todavia, já há probabilidade das novas tecnologias procederem a leitura e a decodificação da palavra para o meio virtual, o que tornaria desnecessária a habilidade própria de alfabetização para a candidatura (FERREIRO, 2013). Cada vez mais a informação chega a todo independente da capacidade de escrita. Nesse mister, a crise da educação formal aponta para remodelação do ensino mais pragmático, utilizando as invenções pós-modernas a seu favor. Numa democracia representativa, é imprescindível o debate de ideias, a representatividade, o objetivo do interesse comum para pluralidade da democracia e o convício da comunidade. Mais importante do que decodificar palavras registradas, está na capacidade de argumentar, interpretar, raciocinar, atributos que, embora corroborados com o domínio da escrita, não são consectários desta. Um analfabeto com larga experiência de vida é capaz de discutir sobre a condução da vida política e dos programas de governo que ele almeja. Portanto, o prognóstico do art. 14 da Constituição aponta para obsolescência quanto a sua razoabilidade tal como os artigos do Ato das Disposições Constitucionais Transitórias ADCT.

\section{ANALFABETISMO EM LÍNGUA PORTUGUESA, DISCRIMINAÇÃO E DOCUMENTOS INTERNACIONAIS}


A Convenção Internacional sobre a Eliminação de Todas as Formas de

Discriminação Racial ${ }^{11}$ é norma de direito internacional, a fim de combater a discriminação racial em todo planeta, significando qualquer distinção, exclusão, restrição ou preferência fundadas na raça, cor, descendência ou origem nacional ou étnica. Nela prevê a instituição de um Comitê para a Eliminação da Discriminação Racial (doravante denominado "o Comitê") formado por " 18 peritos reconhecidos pela sua imparcialidade e alta estatura moral, que serão eleitos pelos Estados Partes dentre seus nacionais e exercerão suas funções a título individual" ${ }^{\prime 12}$. Considera ainda uma repartição geográfica equitativa e as distintas formas de civilização e os principais sistemas jurídicos.

Nesse sentido, as observações finais do Comitê para a Eliminação da Discriminação Racial sobre os países América Latina e Caribe, no período 1970-2006apontaram que “[...] persistem as desigualdades profundas e estruturais que afetam as comunidades negras e mestiças, e as populações indígenas" (RELATÓRIO...1970-2006). Outro ponto é a menção da segregação social de negros, de mestiços e de indígenas em áreas urbanas e rurais e a impossibilidade de que pessoas analfabetas ocupem cargos públicos - um obstáculo ao exercício da cidadania (VITORELLI, 2016. p. 65).

O enfoque do artigo, dessa forma, vai ao encontro da denúncia ao sistema jurídicoconstitucional no qual pessoas analfabetas não podem ocupar cargos públicos, notadamente os políticos. Enquanto aos demais de provimento de provas ou provas e títulos, algumas

\footnotetext{
${ }^{11}$ Artigo1 $^{\circ}$ §1. Para fins da presente Convenção, a expressão "discriminação racial" significará toda distinção, exclusão, restrição ou preferência baseada em raça, cor, descendência ou origem nacional ou étnica que tenha por objeto ou resultado anular ou restringir o reconhecimento, gozo ou exercício em um mesmo plano (em igualdade de condição) de direitos humanos e liberdades fundamentais nos campos político, econômico, social, cultural ou em qualquer outro campo da vida pública.

§2. Esta Convenção não se aplicará às distinções, exclusões, restrições e preferências feitas por um Estado Membro entre cidadãos e não-cidadãos.

§3. Nada nesta Convenção poderá ser interpretado como afetando as disposições legais dos Estados Membros, relativas à nacionalidade, cidadania e naturalização, desde que tais disposições não discriminem contra qualquer nacionalidade particular.

§4. Não serão consideradas discriminação racial as medidas especiais tomadas com o único objetivo de assegurar o progresso adequado de certos grupos raciais ou étnicos ou de indivíduos que necessitem da proteção que possa ser necessária para proporcionar a tais grupos ou indivíduos igual gozo ou exercício de direitos humanos e liberdades fundamentais, contanto que tais medidas não conduzam, em conseqüência, à manutenção de direitos separados para diferentes grupos raciais e não prossigam após terem sido alcançados os seus objetivos.

${ }_{12}$ Parte II, Art. VIII da Convenção para Eliminação de Todas as formas de discriminação racial.
} 
objeções podem ser levantadas: necessidade de leitura e escrita no dia a dia do serviço não tecnológico, atos obrigatoriamente escritos ${ }^{13}$.

O quadro se agrava com a constatação de que os analfabetos são minorias raciais, o que legitima a denúncia realizada pelo Comitê. Nesse mister, o art. V, Parte I garante os direitos políticos e de participação do Estado ${ }^{14}$.

No tocante aos grupos não-integrados, a Convenção sobre a Proteção e Promoção da Diversidade das Expressões Culturais, elaborada em 2005 e promulgada pelo Decreto 6.177, de $1^{\circ}$ de agosto de 2007. Nesse diploma internacional, pugna-se pela diversidade cultural e, por conseguinte racial. Estabelecer o alfabetismo em língua portuguesa é uma forma de discriminação internacional dos povos indígenas e não-integrados, que podem dominar outras técnicas de expressão oral ou escrita.

\section{PRECONCEITO LINGUÍSTICO EM SEDE CONSTITUCIONAL}

Nossa Constituição, portanto, é discriminatória (art. $14 \mathrm{CF}$ ). Todavia, estabelecer critérios de distinção é,intrinsecamente, ligado ao ser humano e às possibilidades de realizar escolhas. Escolhe-se tanto individualmente, quanto coletivamente.

A definição legal de discriminação racial (jurídica) é o ato que, em virtude da raça, distingue, exclui ou restringe o reconhecimento, gozo ou exercício de direitos em qualquer campo da vida pública ou privada. Distingue-se da desigualdade (fática), que é o estado, a situação já verificada, na qual um indivíduo ou grupo não consegue acessar ou fruir os bens sociais em igualdade de condições com o restante da população (VITORELLI, 2016. p. 65).

População negra é o conjunto de pessoas que se autodeclaram pretas e pardas, conforme quesito cor ou raça usado pela Fundação instituto Brasileiro de Geografia e Estatística (IBGE), ou que adotam autodefinição análoga.

\footnotetext{
${ }^{13}$ Art. $50 \S 2^{\circ}$ As Mesas da Câmara dos Deputados e do Senado Federal poderão encaminhar pedidos escritos de informações a Ministros de Estado ou a qualquer das pessoas referidas no caput deste artigo, importando em crime de responsabilidade a recusa, ou o não - atendimento, no prazo de trinta dias, bem como a prestação de informações falsas. (Redação dada pela Emenda Constitucional de Revisão nº 2, de 1994)

${ }^{14}$ Acordo com as obrigações fundamentais enunciadas no artigo 2 desta Convenção, os Estados Partes comprometem-se a proibir e a eliminar a discriminação racial sob todas as suas formas e a garantir o direito de cada um à igualdade perante a lei, sem distinção de raça, de cor ou de origem nacional ou étnica, nomeadamente no gozo dos seguintes direitos: c) direitos políticos, especialmente o de participar de eleições - votando e sendo votado - através de sufrágio universal e igual, direito de tomar parte no governo assim como na direção dos assuntos públicos em todos os escalões, e direito de ter acesso em igualdade de condições às funções públicas;
}

Rev. de Teorias da Justiça, da Decisão e da Argumentação Jurídica | e-ISSN: 2525-9644 | Porto Alegre | v. 4 | n. 2 | p. 01 - 15 | Jul/Dez. 2018 
O preconceito linguístico é a manifestação de discriminação negativa de um determinado indivíduo por conta de seus modos de se expressar, seus regionalismos e pela forma com que lida com a língua(ANDIJK ,2008; LEITE, 2008; LUFT, 2004). Numa análise ampla, o preconceito linguístico incide sobretudo face aos analfabetos, os quais, por não terem acesso à convenção da norma culta, expressam-se de forma desconforme a esta, sendo preteridos ou alvo de chacota nos meios de comunicação ${ }^{15}$.

Assim, causa estranheza quando em um pronunciamento oficial há erros de português, má compreensão verbal ou oral. Todavia, na maior parte dos cargos ao Poder Legislativo - o quais são eleitos majoritariamente os candidatos -, há um predomínio de um debate oral, de ideias e posicionamentos divergentes. Todavia, a maior parte das experiências no legislativo são compartilhadas por um grupo que obteve subsídios nas fases mais tenras da vida, quando o ideal de pluralidade se baseia no máximo de vivências possíveis. O que deveria causar estranheza não era possuir um representante analfabeto, mas ainda haver pessoas sem acesso à educação por ineficácia estrutural no Brasil.

O preconceito linguístico mostra-se como uma barreira estrutural da sociedade para discriminação e esconder a sua própria responsabilidade (BAGNO, 2007). Ademais, a educação também é dever da sociedade, que deverá prestá-la aos mais necessitados ${ }^{16}$. Se houve falha na prestação do serviço público, não é recomendável o agravamento do dano restringindo os direitos políticos de determinado cidadão, mostrando hipótese de impacto desproporcional ${ }^{17}$. Isto porque a proibição transcende a margem de razoabilidade e incide o gravame de forma mais contundente nos hipossuficientes.

\section{POSSÍVEIS CAMINHOS PARA UMA INTERPRETAÇÃO PRO VULNERÁVEL DOS RESTRIÇÕES AO ANALFABETO}

\footnotetext{
${ }^{15}$ Um dos exemplos na literatura infantil é o personagem do Maurício de Souza Cebolinha, o que intercambia o uso das letras " $\mathrm{l}$ " e "r" em diversas palavras. Na televisão e nas redes sociais, comumente há piadas com personagens humorísticos ou brasileiros que se expressam desconforme com a linguagem culta.

${ }^{16}$ Art. 205. A educação, direito de todos e dever do Estado e da família, será promovida e incentivada com a colaboração da sociedade, visando ao pleno desenvolvimento da pessoa, seu preparo para o exercício da cidadania e sua qualificação para o trabalho.

${ }^{17}$ Nesse sentido, adota-se os conceitos constantes em Daniel Sarmento (2006) e Joaquim Barbosa (2001) de teoria do impacto desproporcional.
}

Rev. de Teorias da Justiça, da Decisão e da Argumentação Jurídica | e-ISSN: 2525-9644 | Porto Alegre | v. 4 | n. 2 | p. 01 - 15 | Jul/Dez. 2018 
Considerando que a proibição do estatuto jurídico do analfabeto, quanto aos direitos políticos é desarrazoada e na tendência de busca de proposições para modificação do quadro atual, observar-se-á a possibilidade de novas interpretações ou procedimentos. Inicialmente, deve-se observar que a norma está em patamar constitucional originariamente e, portanto, constitui a Constituição Formal. Ademais, não se adota a tese das normas constitucionais inconstitucionais de Oto Von Banhof, uma vez que a Constituição não possui hierarquização formal entre os seus dispositivos (BANHOF, 2014, p. 23). A tese de declaração da inconstitucionalidade, no Brasil, poderia acarretar numa ruptura sistêmica (unidade da constituição, rigidez constitucional, interpretação conforme e demais princípios de hermenêutica constitucional ficariam esvaziados). Nesse sentido, é o posicionamento do Supremo Tribunal Federal ${ }^{18}$, não sendo o caminho intrassistêmico mais célere.

Há a possibilidade de mutação constitucional (FERRAZ, 1986. p. 80) do art. 14, o qual, ainda que haja manutenção literal do texto, a interpretação da norma mostra-se distinta tal como ocorrido na ADPF 132/RJ e ADI 3277/DF (caso das uniões homoafetivas), em que ainda que haja a expressão homem e mulher no art. 226 da Constituição Federal, não se proíbe outras formas de relacionamento. Nesse sentido, em que pese a proibição expressa da norma, com as normas formas de leitura, considerar-se-á mais a expressão oral e a capacidade argumentativa do membro do Poder Legislativo, restringindo o âmbito normativo para não alcançar aos candidatos ao Poder Legislativo.

Recomenda-se ainda que o Congresso Nacional, em sua competência de Poder Constituinte Derivado ${ }^{19}$ emenda a Constituição Federal a fim de ampliar a participação dos analfabetos, podendo estes serem votados e exercer obrigatoriamente o exercício do sufrágio.

\footnotetext{
${ }^{18}$ As cláusulas pétreas não podem ser invocadas para sustentação da tese da inconstitucionalidade de normas constitucionais inferiores em face de normas constitucionais superiores, porquanto a Constituição as prevê apenas como limites ao poder constituinte derivado ao rever ou ao emendar a Constituição elaborada pelo poder constituinte originário, e não como abarcando normas cuja observância se impôs ao próprio poder constituinte originário com relação às outras que não sejam consideradas como cláusulas pétreas, e, portanto, possam ser emendadas. [ADI 815, rel. min. Moreira Alves, j. 28-3-1996, P, DJ de 10-5-1996]

${ }^{19}$ Distingue poder constituinte (legitimidade para construir uma Constituição Jurídica inaugurando uma nova ordem jurídica) e competência reformadora (não pode ser poder, tampouco constituinte derivado, mas sim órgãos com competência para promover modificações na Constituição jurídica, tendo procedimento diverso). Poder constituinte é um poder jurídico constituído pelos seguintes elementos: soberania, pluralismo e sociedade civil. Entendido como eficácia atual, produto das forças reais de poder expressas pelos núcleos de decisão formados pelos integrantes da sociedade civil, que participam da formação da vontade coletiva e institucionalizam-na, criando uma ordem jurídica nova. No plano lógico, é uma formação histórica efetiva a fim de criar uma ordem nova. Potência é tipo específico de poder, é potestade (Camões) prerrogativa de gabarito divino, de arbítrio sem condicionantes, salvo as consistentes nos objetivos permanentes da sociedade civil que o legitima (direito e garantias fundamentais preservados pelo direito internacional). Ao contrário, é competência quando derivam de autoridade formalmente constituída. (BRITO, 2013. 49-50).
}

Rev. de Teorias da Justiça, da Decisão e da Argumentação Jurídica | e-ISSN: 2525-9644 | Porto Alegre | v. 4 | n. 2 | p. 01 - 15 | Jul/Dez. 2018 
Retirar-se-ia do campo interpretativo, aliando ao sistema de direito de minorias e de proteção aos vulneráveis.

\section{CONCLUSÕES}

O regime jurídico dos analfabetos é permeado de preconceitos e idiossincracias. No intuito de tutelar uma suposta meritocracia, esconde-se a responsabilidade estatal em educar os seus habitantes, bem como homogeneizar a identidade nacional através da língua, inoportunizando que minorias participem no processo eleitoral.

A escrita encontra, interdependente da atuação estatal, desde sua origem com a instituição da burocracia e da necessidade de contabilização e de compartimentalização, ordenando o raciocínio mítico anterior. Assim, difunde-se vinculação da imprescindibilidade da necessidade de alfabetização para ocupar as carreiras do Estado, ainda que seu acesso não seja a partir de qualquer prova ou títulos, mas candidatura e votação significativa dos representados.

Por via formal ou informal de modificação da Constituição Federal, dever-se-ia realizar a modificação do estatuto dos direitos políticos do analfabeto face a (a) modificação da escrita face às novas tecnologias; (b) pluralismo de ideias no âmbito parlamentar; (c) desproporcionalidade da proibição em face dos grupos mais vulneráveis (mais pobres e minorias não integradas).

O preconceito, com a inabilidade com o uso da língua, deve ser combatido, posto que é responsabilidade da própria sociedade promover a educação, sendo alvo de crítica no âmbito dos direitos humanos, a política meritocrática brasileira de prestígio dos letrados em língua portuguesa. O modelo de Estado plural, que abarca diversos povos, mostra-se como saída para a inclusão social não somente nos espaços públicos como no parlamento.

\section{REFERÊNCIAS}

Rev. de Teorias da Justiça, da Decisão e da Argumentação Jurídica | e-ISSN: 2525-9644 | Porto Alegre | v. 4 | n. 2 | p. 01 - 15 | Jul/Dez. 2018 
ANALFABETISMO NO MUNDO DO TRABALHO. Habilidades de Leitura, Escrita e Matemática são limitadas em muitos setores da economia brasileira, podendo restringir produtividade e capacidade de inovação. Disponível em:

<http://download.uol.com.br/educacao/2016_INAF_\%20Mundo_do_Trabalho.pdf.>Acesso em: 23.07.2018.

ANDIJK, Teun A. V..Discurso e poder. São Paulo: Contexto, 2008.

APPIO, Eduardo. Direito das Minorias. São Paulo: Revista dos Tribunais, 2008.

BAGNO, Marcos. Preconceito linguístico. O que é, como se faz. 49. ed. São Paulo: Edições Loyola, 2007.

BANHOF, Oto Von. Normas constitucionais inconstitucionais? Coimbra: Almedina, 2014.

BARBOSA, Joaquim. Ação afirmativa no Brasil?In: Revista da AJUFE, 2001.

BARREIROS NETO, Jaime. Direito Eleitoral.8. ed. Salvador: JusPodium, 2018

BETHENCOURT, Francisco. Racismos. São Paulo: Companhia das Letras, 2018.

BRITO, E. P.. Jurisdição Constitucional: Controle de Constitucionalidade no Direito

Brasileiro. Inconstitucionalidades das Reformas. Efetividade dos Direitos Fundamentais.

Revista Erga Omnes, v. 7, p. 35-52, 2013.

CARVALHO, José Murillo de. Cidadania no Brasil: o longo caminho. 24. ed. Rio de Janeiro: Civilização Brasileira, 2018.

CHIAVENATO, Idalberto. Introdução a Teoria da Administração: modelo burocrático de organização. 7. ed. São Paulo. Editora Campus, 2004.

CUNHA JUNIOR, Dirley da. Curso de direito constitucional.10. ed. Salvador: JusPodium, 2016.

FERRAZ, Ana Cândida da Cunha. Processos informais de mudanças da Constituição. São Paulo: Max Limonad, 1986.

FERREIRO, E. Alfabetização digital. Do que estamos falando. IN: FERREIRO, E. O ingresso na escrita e nas culturas do escrito. São Paulo. Cortez, 2013.

FOUCAULT, Michel. Microfísica do poder. São Paulo: Paz \& Terra, 2008.

FRADE, I. C. A. S. Alfabetização digital: problematização do conceito e possíveis relações com a pedagogia e com aprendizagem inicial do sistema de escrita. In: COSCARELLI, C. e RIBEIRO, E. (orgs.). Letramento digital: aspectos sociais e possibilidades pedagógicas. Belo Horizonte: Autêntica, 2005.

GUIMARÃES, Ary. Constituinte de 1988. Retratos de uma época. Salvador: Assembleia Legislativa da Bahia, 2011.

HARARI, YuvalNoah. Sapiens. São Paulo: Companhia das Letras, 2018.

LEITE, Marli Quadros. Preconceito e intolerância na linguagem. São Paulo: Contexto, 2008.

LUFT, Celso Pedra. Língua e liberdade. São Paulo: Editora Ática, 2004.

MAIA, Napoleão Nunes. Coronelismo, enxada e voto: O município e o regime representativo no Brasil.7. ed. São Paulo: Companhia das Letras, 2012.

Rev. de Teorias da Justiça, da Decisão e da Argumentação Jurídica | e-ISSN: 2525-9644 | Porto Alegre | v. 4 | n. 2 | p. 01 - 15 | Jul/Dez. 2018 


\section{PRECONCEITO LINGUÍSTICO E ASPECTOS JURÍDICOS: A INCLUSÃO POLÍTICA ATRAVÉS DA ALFABETIZAÇÃO NO SÉCULO XXI}

MARTINS, Carlos Eduardo Berhmann Rátis. Introdução ao estudo dos deveres fundamentais. Salvador: JusPodium, 2011.

NO BRASIL, apenas $8 \%$ têm plenas condições de compreender e se expressar. Disponível em:<https://educacao.uol.com.br/noticias/2016/02/29/no-brasil-apenas-8-escapam-doanalfabetismo-funcional.htm?cmpid=copiaecola $>$. Acesso em: 19.07.2018.

OS ÍNDIOS ISOLADOS. Disponível em:<https://www.survivalbrasil.org/povos/indiosisolados-brasil>. Acesso em: 23.07.2018.

PLATÃO. A República. São Paulo: Perspectiva, 2016.

RELATÓRIO do Comitê para a Eliminação da Discriminação Racial sobre os países América Latina e Caribe, 1970-2006.

SARMENTO, Daniel. Livres e Iguais. Estudos de Direito Constitucional. Rio de Janeiro: Lumen Juris, 2006.

SCHWARTZ, Lilia Moritz. Lima Barreto: Triste Visionário. São Paulo: Companhia das Letras, 2018.

VIEIRA, Oscar Vilhena. Direitos Fundamentais: uma leitura da jurisprudência do STF. 2. ed. São Paulo: Malheis, 2017.

VITORELLI, Edilson. Estatuto da igualdade racial.2.ed. Salvador: JusPodium, 2016. 